\title{
Effectiveness of a multimedia resource in histopathology practical teaching in medical undergraduates a comparative study
}

\author{
Subitha K ${ }^{1}$, Lillykutty Pothen ${ }^{2}$, Sajith Kumar $\mathbf{R}^{3}$, Kandamuthan $\mathbf{M}^{4}$, Usha Poothiode ${ }^{5}$ \\ ${ }^{1}$ Dr. Subitha K, Assistant Professor, Department of Pathology, Goverment Medical College, Kottayam (Dist), Kerala, \\ India, ${ }^{2}$ Dr. Lillykutty Pothen, Associate Professor, Department of Pathology, Goverment Medical College, Kottayam \\ (Dist), Kerala, India, ${ }^{3}$ Dr. Sajith Kumar R., Professor, Department of Infectious Diseases, Goverment Medical College, \\ Kottayam, ${ }^{4}$ Mr. M. Kandamuthan, Professor of Biostatistics, DMWIMS, Wayanad, ${ }^{5}$ Dr. Usha Poothiode, Professor, \\ Department of Pathology, MOSC Medical College, Kolenchery, Kerala, India.
}

Address for Correspondence: Dr. Subitha K, Assistant Professor, Department of Pathology, Goverment Medical College Kottayam, Gandhinagar, Kerala. Email: subitha@rediffmail.com

\begin{abstract}
Introduction: Computer technology is found to be a valuable tool to add to the medical teacher's tool kit. This study was done to assess whether learning through digitalized images have advantage over conventional methods in learning histopathology practical. Method: Digital images of another set of 20 slides and specimens were taken and were made into a CD. From a total number of 30 students, 15 students were randomly selected by lot method and they were the study group and the rest 15 students were the control group. Total of 20 slides and specimens were taught in 5 classes over a period of one month. The control group students attended 5 classes where they were taught by conventional methods. The study group, in addition to teaching by conventional method was shown the CD pictures. Assessment was done for both groups as a post test in the form of a spotter exam which included 10 slides and 10 specimens. Result: Mean improvement by the newer method was found to be 18.6 with a standard deviation of 23.3 and this improvement was statistically significant as $\mathrm{t}=2.87$ and $\mathrm{p}$ value $<.01$. The mean score obtained by the students by conventional method was $53 \%$ whereas the mean score obtained by the students by the newer method was $67 \%$. Discussion: The incorporation of digital images in teaching histopathology practical's combined with the conventional method of teaching showed a statistically significant change in learning.
\end{abstract}

Key words: Histopathology practicals, Digital images, Conventional method

\section{Introduction}

Pathology is a discipline that bridges clinical practice and basic science, and it involves the etiology of disease as well as the pathogenesis that result in the presenting signs and symptoms of the patient [1]. Histology is the study of normal structure. Structure always follows function and histology is therefore a tool for determining the function of different tissues and organs. When tissues malfunction, e.g. in certain disease states such as cancer or inflammation, there are often specific changes in the microscopic structure of the tissues. The study of these changes is known as histopathology. Obviously a sound knowledge of normal structure is essential for an understanding of pathology [2].

Manuscript received: $10^{\text {th }}$ October 2016

Reviewed: $25^{\text {th }}$ October 2016

Author Corrected: $10^{\text {th }}$ November 2016

Accepted for Publication: $27^{\text {th }}$ November 2016
Practical sessions are an important component in the teaching and learning of histopathology. Histopathology practicals are conventionally taught in our institution using lectures and PowerPoint slides. At the end of a brief introductory lecture on the slides and specimens allotted for that practical session, each student is given the slides which they focus on the microscope they are given. Most of the time the area to be focused will not be known by the students and they are assisted by the teachers. Some of the less interested students don't take the assistance of the teachers at all. They leave the practical hall without seeing any slides. Assessment is usually done at the end of the semester. Before the assessment exams revision classes are given during which the students can see the slides kept focused on the microscopes. The specimens are arranged with 


\section{Research Article}

pamphlets containing a brief description of each. The students can see it on their own. For the assessment, specific areas on slides would be focused which shows the hallmark identifying features which will help in diagnosis. Specimens are kept for spotter exams and viva where the students are expected to describe the specimen and give a diagnosis and answer the related questions. This study was undertaken to assess whether learning through digitalized images have advantage over conventional methods in learning histopathology practicals in MBBS curriculum.

\section{Materials and Methods}

In conventional method of teaching of histopathology practicals the classes are taken with the help of lectures and Power Point slides. The Power Point slides are made from pictures available on the internet. The students are shown 4 slides and 4 specimens given in their curriculum in one class. There will be a brief lecture in the beginning of every class with the help of Power Point slides. In the practical sessions, performed in microscopy laboratories, every student use a light microscope to examine glass slides for a limited time.

Development of multimedia resource was by taking photographs of 20 slides and specimens which is part of the 2 nd MBBS practical curriculum. (Fig: 1)This was made into a CD.

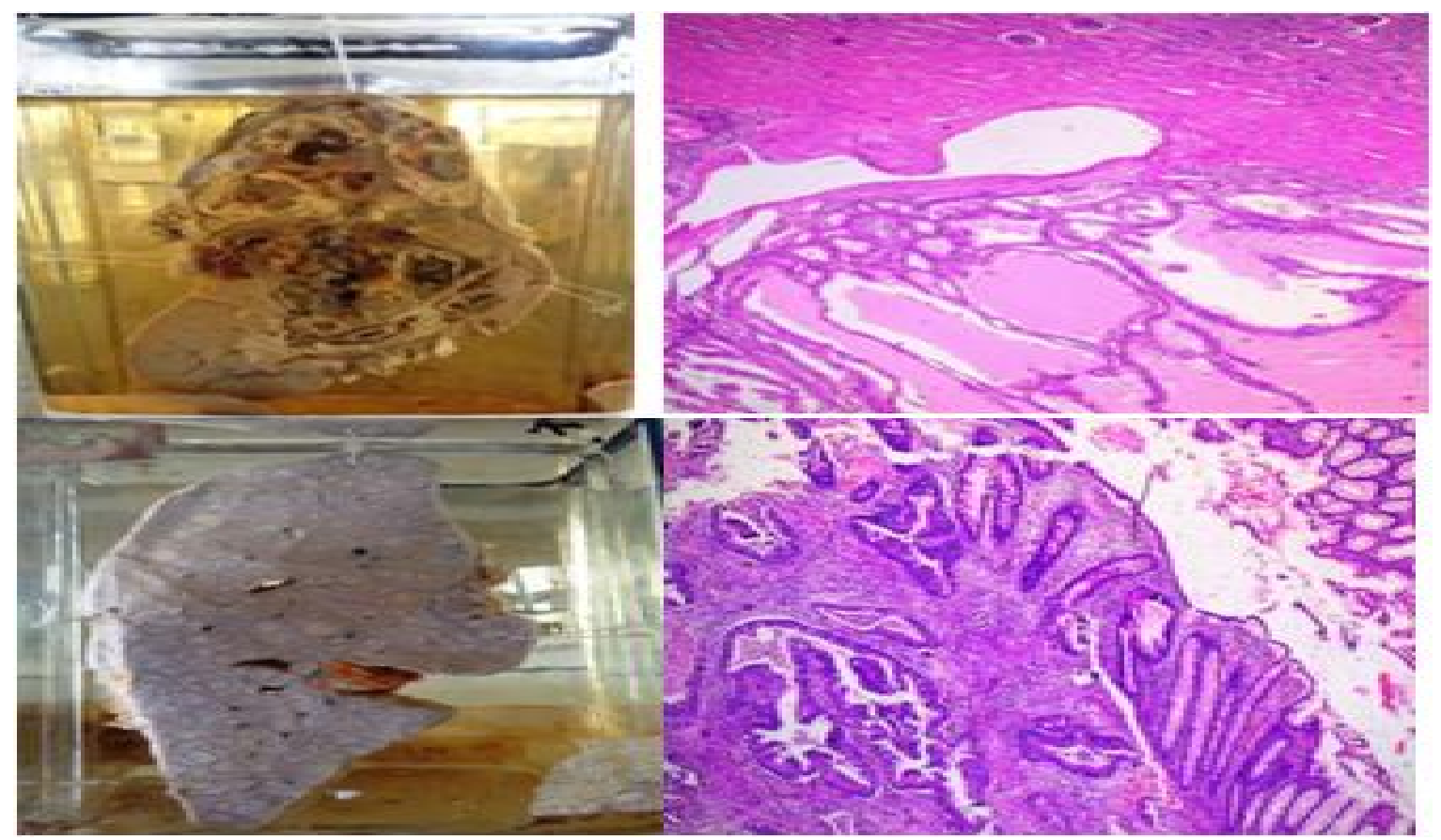

Figure-1: Digital images of gross specimens and histopathology slides

From a total number of 30 students, 15 students were randomly selected by lot method and they were the study group and the rest 15 students were the control group. Total of 20 slides and specimens were taught in 5 classes over a period of one month. Both the groups were given a pretest in the form of short answer questions before each class.

The control group students attended 5 classes where they were taught by conventional methods. The study groups, in addition to teaching by conventional method were shown the CD pictures and a soft copy of the CD was given to each of the students which they could watch at home or they could avail facilities in the department for viewing the $\mathrm{CD}$ in groups. The pictures could be viewed on their laptops or even mobiles through social media. At the end of the month when all the 20 slides and specimens were taught to both groups, assessment was done for both groups as a post test in the form of a spotter exam which included 10 slides and 10 specimens.

After the post test of both the groups, the control group were shown the CD pictures and a copy was given to them. A questionnaire was given to the study group to assess student perception regarding the use of multimedia resource as a teaching tool. Informed consent was obtained from all the students. 


\section{Results}

Post test in both conventional and newer method showed a significant improvement in learning. Mean improvement by the newer method was found to be 18.6 with a standard deviation of 23.3 and this improvement was statistically significant as $\mathrm{t}=2.87$ and $\mathrm{p}$ value $<.01$. (Table: 1 ) The mean score obtained by the students by conventional method was $53 \%$ whereas the mean score obtained by the students by the newer method was $67 \%$. (Table: 2 ).

Table-1: Mean improvement of students.

\begin{tabular}{|c|c|c|c|c|c|c|}
\hline & Conventional & Newer & Mean improvement & SD & Paired t value & P value \\
\hline Mean & $53 \%$ & $67 \%$ & 18.6 & 23.3 & 2.87 & $<.01$ \\
\hline
\end{tabular}

Table-2: Mean score obtained by the students.

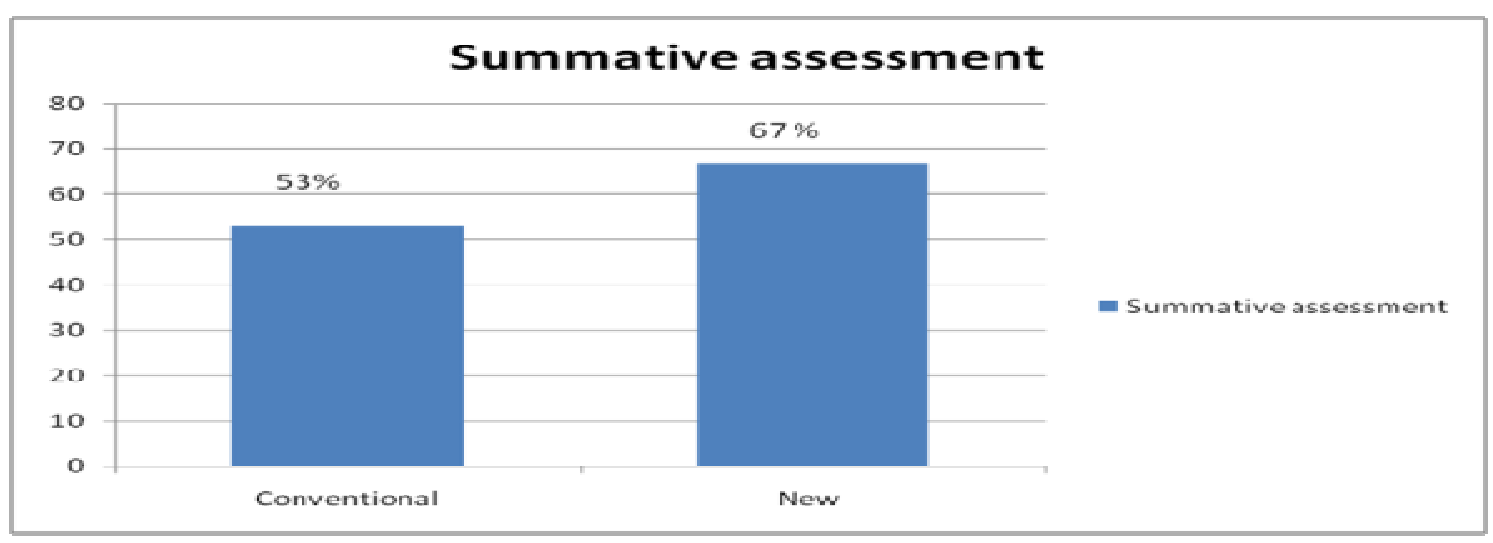

Feedback- Students of histopathology practical classes readily accepted the use of digital images for learning the pathology slides and specimens. All students found the learning of pathology practicals by digital images useful and wanted multimedia resource to be a medium of education in medical colleges. All the students wanted histopathology practicals to be taught by combining conventional method with digital images.

\section{Discussion}

Computer technology is found to be a valuable tool to add to the medical teacher's tool kit [3]. Use of digitalised flex sheets as a new teaching modality was widely accepted by students and faculty [4]. In a study by Ackermann, it was seen that the microscope can be successfully replaced by an instructive way of learning like a video or a multimedia computer presentation [5]. In another study by A. P. Choules, computer technology was found to be reliable and reusable in a format that is convenient to the learner [3]. There has been a revolutionary advance in information technology and communication and this has positively enhanced every aspect of our day to day life. Lorna et al did a study to test the feasibility of a fully digital examination by comparing the performance of senior pathology residents in completing the examination using glass slides versus digital images and to test whether more time is needed to navigate through digital images [6]. They found that digital whole-slide scanned images are of comparable efficiency to glass slides for diagnostic purposes. About a third of American medical schools have incorporated digital wholeslide images into their pathology training [6]. Laszlo did a pilot study for introducing digital microscopy in graduate histopathology teaching in Hungary and to establish an open access digital slide set for medical students [7].

He found that digital slides could easily be integrated to histopathology education. These results emphasized the importance of the "human factor" in the efficiency of the installation of any new techniques [7]. In the field of cytopathology, digital images are used in a variety of settings including education, as a substitute to multiheaded sessions, multisite conferences, publications, cytopathology web pages, cytology proficiency testing, telecytology, consultation through telecytology, and automated screening of Pap test slides [8]. Khalbuss et al studied recent advances in the field of digital imaging in cytopathology, its various applications and potential uses in cytopathology, and the current limitations and barriers of digital imaging in cytopathology [8]. 


\section{Research Article}

Younger generations are more knowledgeable about technology than the adults and are using it in their routine activities. More students are using mobile devices to access the services of e-learning. However, the adoption of technology has been very slow in educational institutions. These innovative techniques can very well be used to teach pathology.

When you use digitalized images the advantage is that there is a continuous exposure to the slides and the students can access it anywhere and revise it anytime at their own pace. There is a standardization of knowledge transmitted to the students. The students found it more convenient as they could save it to their mobiles and share it through whatsapp and other social media and this helped them in self revisions. They could familiarize with the slides and specimens even without visiting the practical lab. On the part of the teachers, lesser effort was needed for revisions. Once a set of digitalized images were made it could be used for all batches of students with modifications once in a while.

\section{Conclusion}

The incorporation of digital images in teaching histopathology practicals combined with the conventional method of teaching showed a statistically significant change in learning. Digital images have a better impact on students in learning histopathology practicals. Students evaluated positively their use of digital images for learning histopathology practicals. They found it to be more independent and student friendly. Students should be familiarized with usage of light microscopes. So the conventional method of learning need not be stopped. The conventional method can be combined with use of digital images to ensure better learning.

The availability of the Internet and advancements in information technology has created a revolutionary change in acquisition of knowledge. This can be positively used in progressively expanding the pathology programs and other disciplines of medicine. More infrastructure and computer facilities should be made available at institutions.
Since it was practical session, this study was done on a small number of students. This can be used on a large group of students using larger number of slides and specimens and incorporating a larger manpower.

Funding: Nil, Conflict of interest: None initiated, Permission from IRB: Yes

\section{References}

1. Kumar V, Abbas AK, Fausto N, Aster JC. Robbins and Cotran pathologic basis of disease. Elsevier Health Sciences; 2014 Aug 27.

2.Young B, Heath JW. Wheater's functional histology, 4th edi. Churchill Livingstone. 2000.

3. Choules AP. The use of elearning in medical education: a review of the current situation. Postgrad Med J. 2007 Apr;83(978):212-6.

4. Gupta G, Chhabra SU, Singh KA. Innovative method of teaching histology. International Journal of Recent Advances in Pharmaceutical Research. 2012;2(1):33-6.

5. Ackermann PC. The suitability of a multimedia resource for teaching undergraduate histology in a developing country (Doctoral dissertation).

6. Mirham L, Naugler C, Hayes M, Ismiil N, Belisle A, Sade S, Streutker C, MacMillan C, Rasty G, Popovic S, Joseph M. Performance of residents using digital images versus glass slides on certification examination in anatomical pathology: a mixed methods pilot study. CMAJ open. 2016 Jan;4(1):E88.

7. Fónyad L. Utilizing digital pathology applications in teaching, routine surgical pathology and in research (Doctoral dissertation, Semmelweis University).

8. Khalbuss WE, Pantanowitz L, Parwani AV. Digital imaging in cytopathology. Patholog Res Int. 2011; 2011:264683. doi: 10.4061/2011/264683. Epub 2011 Jul 19.

\section{How to cite this article?}

Subitha K, Lillykutty Pothen, Sajith Kumar R, Kandamuthan M, Usha Poothiode. Effectiveness of a multimedia resource in histopathology practical teaching in medical undergraduates-a comparative study. Trop J Path Micro 2016;2(3):168171.doi: 10.17511/jopm.2016.i03.15 